\title{
Visualisation of Bacterial Behaviour using Tapping-Mode Atomic Force Microscopy
}

\author{
N. Gorham ${ }^{1, a}$, T. Becker ${ }^{1, b}$, D.W. Shiers ${ }^{2, c}$ and H.R. Watling ${ }^{2, d}$ \\ A.J. Parker Cooperative Research Centre for Integrated Hydrometallurgy Solutions, \\ ${ }^{1}$ Nanochemistry Research Institute, Curtin University of Technology, GPO Box U1987, Perth, \\ Western Australia 6845, Australia. \\ ${ }^{2}$ CSIRO Minerals, PO Box 7229, Karawara, Western Australia 6152, Australia. \\ an.gorham@curtin.edu.au, b t.becker@curtin.edu.au, \\ ${ }^{c}$ denis.shiers@csiro.au, ${ }^{d}$ helen.watling@csiro.au
}

Keywords: Tapping-mode AFM, In situ AFM, Sulfobacillus

\begin{abstract}
Ex-situ and in-situ Tapping Mode AFM were used to investigate responses of attached bacteria to stressful conditions. For ex-situ measurements, the AFM was equipped with a customised re-positioning stage and sample mount to permit re-examination of the same surface area. Initial experiments using Sulfobacillus thermosulfidooxidans indicated that increased acidity promoted EPS production but increased salinity resulted in cell detachment.
\end{abstract}

\section{Introduction}

Since its introduction in 1986 [1], the Atomic Force Microscope (AFM) has been employed in a vast variety of experiments in many fields of science, including visualisation of bioleaching bacteria [2]. Most of all its capability to operate in-situ in most fluids and at a wide temperature range makes the AFM a valuable research tool. However, in recent literature, problems during in-situ imaging such as tip induced movement and/or detachment of the bacteria have been reported [2].

In this study, AFM was used to examine leaching bacteria attached to pyrite. In both ex-situ and in-situ experiments, the AFM was operated in Tapping Mode to ensure that the attached bacteria were not disturbed or detached with the AFM probe. For ex-situ studies, the use of a specially modified sample stage and sample mount allowed repeated re-positioning of a pyrite coupon after exposure to a bacterial culture. Further, with careful choice of operating conditions, it was possible to image bacteria in-situ using Tapping Mode. Measurements were made continuously over a period of several days without causing bacteria to detach. Following the evaluation of stable imaging conditions, the behaviours of attached bacteria subjected to increased acidity or salinity were examined.

\section{Experimental}

Sample Preparation. The pyrite samples were prepared from a cubic piece of pyrite $\left(1 \mathrm{~cm}^{3}\right)$, which was embedded in an epoxy resin and cut into thin slices of approximately $3 \mathrm{~mm}$ thickness. In the next step, the sample slices were manually ground and polished (three grinding steps: \#600, \#1000, \#1200, two polishing steps: $3 \mu \mathrm{m}$ diamond suspension, $1 \mu \mathrm{m}$ diamond suspension). In the case of the ex-situ measurements, a straight edge was cut from the epoxy disk to allow re-positioning under the AFM. The sample disk for the in-situ experiments was cut to size and two holes were drilled into the slice to fit it into the fluid cell holder. All samples were cleaned in ethanol in an ultrasonic bath and with an UV/ozone cleaner prior to exposure to the bacteria solution.

Culture Preparation and Maintenance. Sulfobacillus thermosulfidooxidans DSM $9293^{\mathrm{T}}$ was grown at $45{ }^{\circ} \mathrm{C}$ in BSM-Ye medium [3] supplemented with $10 \mathrm{~g} / \mathrm{L}$ ferrous sulfate. Cultures were grown successively on the media for three subcultures before filtering through a $0.45 \mu \mathrm{m}$ pore size 
membrane. Cells were resuspended into $30 \mathrm{~mL}$ of growth media at a cell concentration of approximately $2.0 \times 10^{8}$ cells $\mathrm{mL}^{-1}$.

\section{Application of AFM to $E x$-situ Investigations}

Instrument and Optimisation. A Digital Instruments Dimension 3100 AFM system (Veeco, California) operated in Tapping Mode with standard Tapping Mode cantilever (NSC-15 NoAl, Mikromasch, Spain) was used for the ex-situ investigations. The motorised sample stage of the AFM was deactivated and an L-shape metal bracket was mounted onto the stage. Sliding the ex-situ coupon with its straight edge along the bracket and pushing it into the corner ensured the repeated positioning of the coupon with an accuracy of better than $10 \mu \mathrm{m}$. The optical microscope of the Dimension 3100 was used as a first control of correct positioning and with the large scan range of the AFM scanner it was always possible to find specific sample features imaged in previous scans.

Some preliminary experiments targeting bacterial behaviour were undertaken by repeatedly exposing the pyrite coupon to a bacterial solution and then examining the same surface area ex-situ. The selected variables were increased acidity or salinity.

Impact of Increased Acidity on Attached Bacteria. Bacterial attachment was promoted by 18hour exposure of pyrite coupons to an $S$. thermosulfidooxidans culture maintained at $45^{\circ} \mathrm{C}$. The coupon was removed from the solution, gently dried with high purity nitrogen and placed on the repositioning stage of the AFM. The pyrite surface was scanned in Tapping Mode with the amplitude setpoint as high as possible in order not to disturb or detach the bacteria. Following a large overview scan $(50 \mu \mathrm{m})$ to locate bacteria on the surface, higher resolution images of selected groups of bacteria were obtained. The coupons were then re-exposed to the bacterial culture for one hour, repositioned on the AFM stage using the customised bracket and the topographical features of the previous scan located within $\pm 5 \mu \mathrm{m}$. Repeated exposures over more than 30 hours revealed the previously attached bacteria as well as newly attached bacteria on the selected surface (Fig. 1).
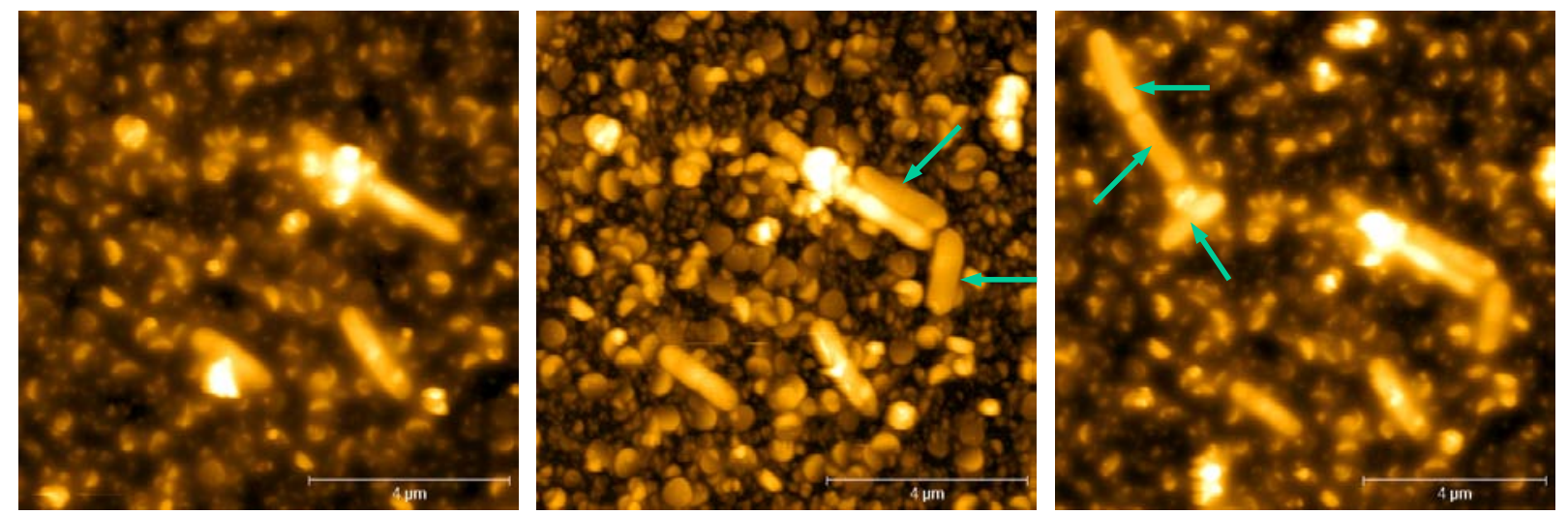

Fig. 1. Ex-situ Tapping Mode AFM imaging using the repositioning stage. The arrows indicate newly attached $S$. thermosulfidooxidans cells in successive images at 18, 19 and 20 hours of the same pyrite surface area.

The acidity of the culture medium was adjusted from $\mathrm{pH} 2.3$ to $\mathrm{pH} 1.3$ with sulfuric acid at 36 hours. Within an hour, the roughness of the pyrite surface increased significantly. Well established groups of bacteria remained on the surface, but recently-attached bacteria were no longer visible and no new bacteria attached (Fig. 2). After a further 20 hours, the surface was 'sticky', evidenced by the need to significantly lower the amplitude setpoint, corresponding to harder tapping on the surface. It was hypothesised that the stickiness was due to bacterial EPS covering the surface and the bacteria. While effects such as attachment, detachment, cell division and/or spore formation were expected possible responses to optimal or stressful growth conditions, copious EPS production was not anticipated and will be confirmed as a response to increased acidity through repeated experiments. 

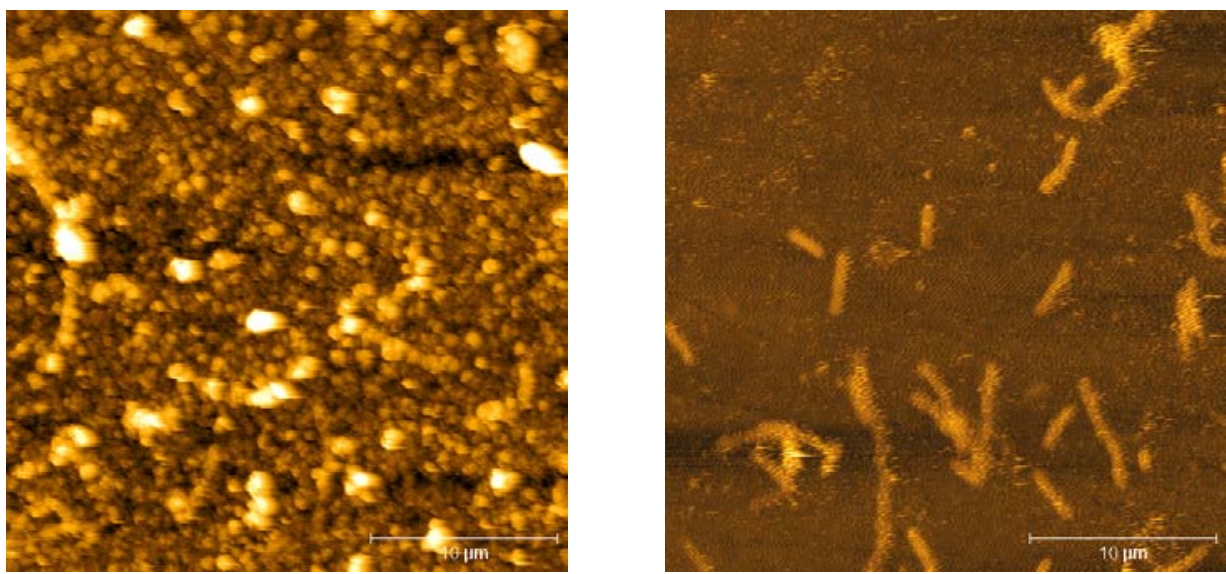

Fig. 2. Ex-situ imaging of the surface after decreasing the $\mathrm{pH}$ of the environment. The left image was taken $1.5 \mathrm{~h}$ after acid addition, the right image was taken at $20 \mathrm{~h}$ after acid addition.

Impact of Increased Salinity on Attached Bacteria. The pyrite coupon was exposed to the culture for 20 hours to achieve bacterial attachment. The salt concentration of the medium was then increased to $5 \mathrm{~g} / \mathrm{L} \mathrm{NaCl}$. The pyrite surface was scanned after 18 hours exposure to the saline bacterial medium. In contrast to the previous experiment, no evidence of surface roughening was detected. However, the orientation between two neighbouring bacteria had changed with respect to the measurement before salt addition and one cell seemed to have partially detached from the pyrite surface. As this might have been induced by the removal and drying of the coupon, detachment as a bacterial response to increased salinity was re-examined with in-situ measurements.

\section{Application of AFM to In-situ Investigations}

Instrument and Optimisation. A Molecular Imaging PicoPlus AFM system (Agilent, Texas) with a fluid flow-through cell mounted on a heating stage was used to investigate the behaviour of bacteria attached to pyrite surfaces. A pyrite coupon was prepared and exposed to the $S$. thermosulfidooxidans culture for 24 hours. The coupon was removed from the culture medium and mounted on the heating stage $\left(\mathrm{T}=45^{\circ} \mathrm{C}\right)$ together with the fluid cell. During this process the sample surface was constantly covered with a film of liquid.

The bacterial culture solution was recirculated between the reservoir and the fluid cell using a peristaltic pump. A small pump-rate was used to avoid large temperature gradients in the fluid cell and to keep the pulsing caused by the pump at a minimum. The system was then left for at least one hour before scanning the sample to allow thermal equilibration. The in-situ Tapping Mode imaging was undertaken using very soft silicon nitride cantilevers with a spring constant of $0.06 \mathrm{~N} / \mathrm{m}$ (type DNP, Veeco, California). The amplitude setpoint was kept as high as possible to avoid tip influenced distortion or detachment of the bacteria during scanning.

With the appropriate imaging parameters and the system fully equilibrated it was possible to scan the surface of the sample over a period of at least 24 hours without detaching bacteria.

Impact of Increased Salinity on Attached Bacteria. Following in-situ Tapping Mode imaging with normal growth medium being recirculated through the fluid-flow cell, the salinity of the growth medium was increased by the addition of $\mathrm{NaCl}(5 \mathrm{~g} / \mathrm{L})$. Whereas the image acquired two hours after salt addition did not show any overt change, the next image (2h 08') clearly shows the partial detachment of a bacterial cell (Fig. 3). In the following frame the bacterium is no longer attached to the surface. Due to the fact that it was possible to image the same area for more than 24 hours without any disturbance of the bacteria, the observed detachment is attributed to the increased salinity of the growth medium. 

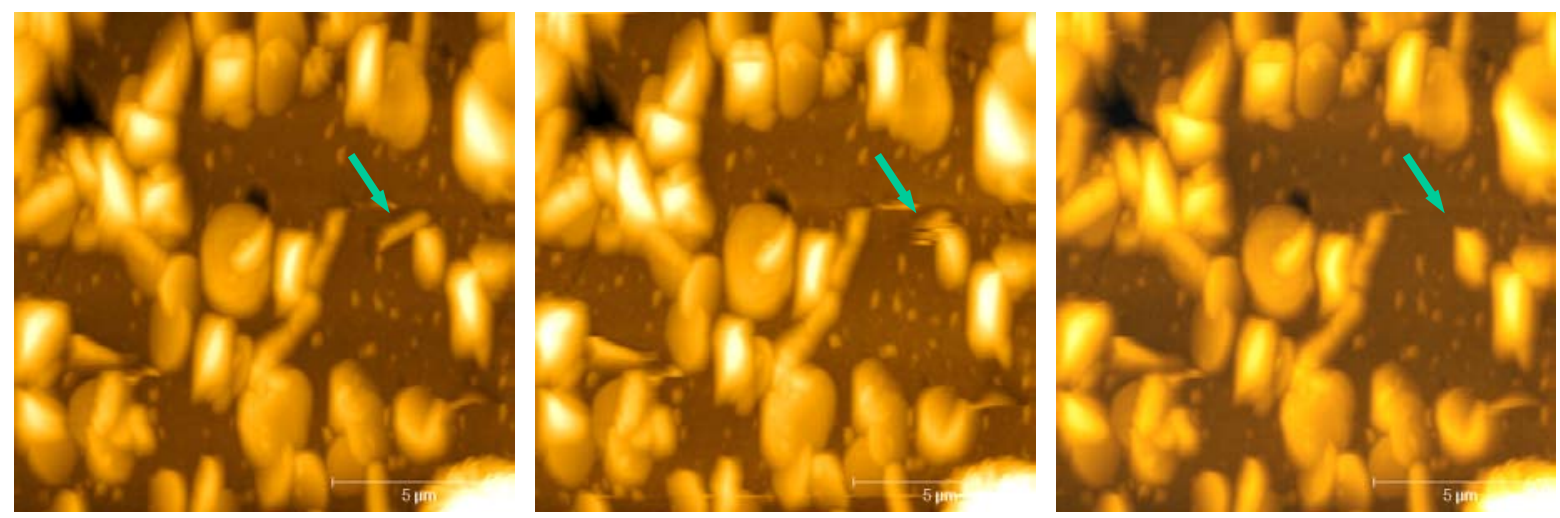

Fig. 3. Successive in-situ AFM image after increasing the salinity of the system (time after $\mathrm{NaCl}$ addition: left: $120 \mathrm{~min}$, centre: $128 \mathrm{~min}$, right: $136 \mathrm{~min}$ )

\section{Summary}

In this study it has been shown that in-situ imaging of $S$. thermosulfidooxidans under variable environmental conditions is feasible. Further, an inexpensive modification that allowed accurate relocation of the sample surface for AFM investigation was demonstrated. Possible bacterial responses to stressful growth conditions were EPS production (acidity) and detachment (salinity). An improved fundamental understanding of the behaviour of bioleaching bacteria under stressful conditions requires better statistics from identically repeated experiments.

\section{Acknowledgement}

The financial assistance of the Australian Government through the AJ Parker Cooperative Research Centre for Hydrometallurgy Solutions is gratefully acknowledged.

\section{References}

[1] G. Binnig, C.F. Quate, and C. Gerber: Phys. Rev. Lett. Vol. 56 (1986), p. 930.

[2] S. Mangold, M. Laxander, K. Harneit, T. Rohwerder. G. Claus, and W. Sand: Hydrometallurgy Vol. 94 (2008), p. 127.

[3] H.R. Watling, F.A. Perrot and D.W. Shiers: Hydrometallurgy Vol. 93 (2008), p. 57. 